\title{
Critical temperatures for radiation enhanced diffusion and metastable alloy formation in ion beam mixing
}

\author{
R. de Reus *, A.M. Vredenberg, A.C. Voorrips, H.C. Tissink, and F.W. Saris \\ FOM-Institute for Atomic and Molecular Physics, Kruislaan 407, 1098 SJ Amsterdam, The Netherlands
}

Received 15 December 1989 and in revised form 28 August 1990

\begin{abstract}
Phase formation, stability, and mixing behavior in the metallic systerms $\mathrm{Ni}-\mathrm{Zr}, \mathrm{Fe}-\mathrm{Zr}, \mathrm{Au}-\mathrm{Zr}$, and $\mathrm{Pd}-\mathrm{Ta}$ have been investigated under influence of high energy heavy ion beams as a function of temperature. Our results and data from the literature support a simple model which correlates onset temperatures for radiation enhanced diffusion and equilibrium phase formation in ion beam mixing with hole (or vacancy) formation enthalpies. The model offers the possibility to predict temperature ranges in which efficient mixing occurs by radiation enhanced diffusion without formation of stable alloys.
\end{abstract}

\section{Introduction}

As first shown by Matteson et al. [1], two different temperature regimes can be distinguished in ion beam mixing. At low temperatures ion beam mixing appears to be temperature independent. In this regime the majority of atomic mixing takes place in well developed collision cascades on time scales of $10^{-11} \mathrm{~s}$. The quantity of intermixed material depends, among others, on the chemical affinity of the elements being mixed [2-6]. A large negative heat of mixing will facilitate the mixing process, whereas a large positive heat of formation will hinder ion mixing. At low temperatures no long range diffusion is possible and metastable phases are formed in almost every case [6,7]. With the aid of Miedema's macroscopic atom model [8] one can compare the thermodynamics of amorphous phases and solid solutions. As shown by Loeff et al. [9], this provides an easy tool in predicting the glass forming range for an arbitrary system consisting of two transition metals. The lower Gibbs free energy determines which metastable phase is expected to form: either the amorphous phase or a (supersaturated) solid solution.

In the higher temperature regime ion mixing becomes strongly temperature dependent. The general belief is that a thermally activated long range diffusion process sets in when defects, generated by the incoming ions, become mobile. This is called radiation enhanced diffusion (RED). The critical temperature for RED, $T_{\mathrm{c}}$, is defined as the temperature at which the temperature-

* Present address: Risø National Laboratory, Physics Department, DK-4000 Roskilde, Denmark. dependent mixing equals the temperature-independent cascade mixing process. Recently, correlation between cohesive energy and $T_{\mathrm{c}}$ has been convincingly shown $[10,11]$. It was demonstrated that $T_{c}$ (in kelvin) is proportional to the activation energy, $Q_{\mathrm{RED}}$, of the effective diffusion coefficient of radiation enhanced diffusion. On the assumption that $Q_{\mathrm{RED}}$ scales with the cohesive energy of solids, $E_{\text {coh }}$, one arrives at the proportionality between $T_{\mathrm{c}}$ and $E_{\mathrm{con}}$. The cohesive energy is the energy required to disassemble a solid into its constituent atoms. In refs. [10] and [11] the cohesive energy was chosen as the average of the cohesive energies of the elements being mixed.

For elementary metals it has been shown [12] that the heat of formation of monovacancies is proportional to the cohesive energy: $\Delta H_{1 \mathrm{v}}=-0.29 E_{\mathrm{coh}}$. In a binary alloy one can distinguish between two types of holes (or vacancies), namely $\Delta H_{\mathrm{VA}_{\mathrm{A}}}$ and $\Delta H_{\mathrm{VB}}$, corresponding to holes the size of $\mathrm{A}$ - and $\mathrm{B}$-atoms respectively. If there is a large difference between $\Delta H_{\mathrm{VA}}$ and $\Delta H_{\mathrm{VB}}$ (e.g. in the systems $\mathrm{Ni}-\mathrm{Zr}, \mathrm{Fe}-\mathrm{Zr}$, Au-Zr), two critical temperatures are expected in ion beam mixing, one correlated with $\Delta H_{\mathrm{VA}}$, the other with $\Delta H_{\mathrm{VB}}$. The lowest critical temperature is correlated with the formation of holes the size of the smaller constituent, $\Delta H_{\mathrm{vsmall}}$. We identify this temperature as $T_{c}$, for radiation enhanced diffusion sets in when the smaller constituent of the alloy becomes mobile. Although RED occurs, this does not necessarily drive the system to equilibrium, as has been shown in several studies on RED in amorphous alloys [13-16]. To form crystal structures of equilibrium compounds collective motion of both constituents is required, as first shown by Schwarz and Johnson and later by other authors [17]. Therefore, a second critical 
temperature in ion beam mixing should exist which is correlated with the formation enthalpy of holes the size of the larger constituent, $\Delta H_{\text {varge. }}$ Above this critical temperature, which we call $T_{\text {eq }}$, formation of equilibrium compounds is expected.

In this paper we will show evidence for these two critical temperatures in the systems $\mathrm{Ni}-\mathrm{Zr}, \mathrm{Fe}-\mathrm{Zr}$, and $\mathrm{Au}-\mathrm{Zr}$. Values of $T_{\mathrm{c}}$ have been determined by Ding et al. [14-16]. Using transmission electron microscopy (TEM), we have observed that above $T_{c}$ the alloys were still amorphous, in agreement with the model proposed above. Furthermore, for these systems we have determined, by means of TEM, at which temperature equilibrium phases form.

Only one critical temperature $\left(T_{\mathrm{c}}=T_{\mathrm{eq}}\right)$ is expected in ion beam mixing of binary alloys for which $\Delta H_{v_{s m a l l}}$ is approximately the same as $\Delta H_{\text {vlarge. First this is }}$ verified in the system $\mathrm{Pd}-\mathrm{Ta}$ and then the correlations of $T_{s}$ and $T_{\mathrm{eq}}$ with $\Delta H_{\mathrm{Vsmall}}$ and $\Delta H_{\text {vtaxge }}$ respectively are compared with available data from literature.

\section{Experimental}

Thin metal films were deposited in a dual e-gun evaporation system with a base pressure less than $5 \times$ $10^{-9}$ mbar. At a typical deposition rate of $3 \AA / s$ the pressure rose to a maximum of $1 \times 10^{7} \mathrm{mbar}$. The substrates, oxidized silicon wafers and cleaved $\mathrm{NaCl}$ single crystals, were kept at liquid nitrogen temperature during deposition. Amorphous $\mathrm{Ni}_{55} \mathrm{Zr}_{45}, \mathrm{Fe}_{55} \mathrm{Zr}_{45}$, $\mathrm{Au}_{50} \mathrm{Zr}_{50}$, and $\mathrm{Au}_{35} \mathrm{Zr}_{65}$ films were deposited onto $\mathrm{NaCl}$ substrates. The composition of the alloys was chosen such that the highest crystallization temperature is expected [18-22]. Not much is known about amorphous $\mathrm{Au}-\mathrm{Zr}$, but according to a model proposed by Barbour et al. [17], a higher stability is expected for amorphous $\mathrm{Au}_{35} \mathrm{Zr}_{65}$ compared to the $\mathrm{Au}_{50} \mathrm{Zr}_{50}$ alloy. The lotal thickness of the films, measured by Rutherford backscattering spectroscopy (RBS), was usually about $500 \AA$. Impurity concentrations of light elements like oxygen, carbon, and nitrogen, were found to be below the detection limit for RBS.

Pd-Ta was studied using multilayer samples. Alternating layers of elemental $\mathrm{Pd}(35 \AA)$ and $\mathrm{Ta}(65 \AA)$ were deposited to a total thickness of $500 \AA$ onto $\mathrm{NaCl}$ single crystals. Complete mixing of the multilayered samples would result in an alloy with a composition $\mathrm{Pd}_{40} \mathrm{Ta}_{60}$. which has been shown to be close to the most stable composition for both thermal annealed and ion irradiated amorphous Pd-Ta at elevated temperatures [23]. To study the temperature dependence of ion beam mixing in the Pd-Ta system, also a bilayer structure of $450 \AA$ $\mathrm{Pd} / 400 \AA \mathrm{Ta}$ was deposited onto an oxidized silicon wafer. The Ta layer was evaporated on top to avoid reaction with the $\mathrm{SiO}_{2}$ substrate and for better separation of the peaks in RBS analysis.

Before ion irradiation, TEM samples were prepared by floating off the $\mathrm{NaCl}$ substrates in deionized water and picking up the metal films on molybdenum TEM grids.

Ion mixing experiments were performed by mounting the samples on a molybdenum block, which could be heated in the temperature range from room temperature to $800^{\circ} \mathrm{C}$ by radiative heating with a hot filament at the backside. The temperature was measured by a pyrometer at the front side of the block, and a platinum resistance inside the block. The accuracy of the temperature measurement of the samples is estimated to be within $\pm 50^{\circ} \mathrm{C}$. A single ended Van de Graaff accelerator [24] was used to produce an $825 \mathrm{keV}^{129} \mathrm{Xe}^{+}$ion beam for the ion irradiations. To minimize beam heating effects, the beam current was kept at $70 \mathrm{nA} / \mathrm{cm}^{2}$. The total fluence was between 0.4 and $5.0 \times 10^{15}$ ions $/ \mathrm{cm}^{2}$. A dose of $1.5 \times 10^{15}$ ions $/ \mathrm{cm}^{2}$ results in 10 displacements per $7 \mathrm{r}$ atom in the $\mathrm{Zr}$-based alloys, as calculated by the TRIM-86 computer code [25]. During irradiation the vacuum was better than $1 \times 10^{-7} \mathrm{mbar}$. In all cases a reference sample was also mounted on the block. These samples were subjected to the same heat treatment as the irradiated samples, but were screened from the ion beam. After irradiation the samples were cooled to room temperature and examined by TEM and RBS with $2 \mathrm{MeV} \mathrm{He}^{+}$. The RBS analysis was done using the RUMP computer code [26].

\section{Results}

\section{1. $\mathrm{Ni}-\mathrm{Zr}, \mathrm{Fe}-\mathrm{Zr}$, and $\mathrm{Au}-\mathrm{Zr}$}

The $\mathrm{Zr}$-alloys were found to show a very similar behavior. All alloys were amorphous as deposited. This is based on observations with TEM: bright field images are structureless and in diffraction mode broad halos are observed. Also, dark field images are homogeneous and structureless.

In fig. $1 \mathrm{TEM}$ results of the $\mathrm{Ni}_{55} \mathrm{Zr}_{45}$ amorphous alloy are shown after ion mixing at elcvated temperatures with $825 \mathrm{keV}^{129} \mathrm{Xe}^{+}$ions to a dose of $1.5 \times 10^{15}$ ions $/ \mathrm{cm}^{2}$. Fig. 1(a) shows that after ion mixing at room temperature the alloy is amorphous. The fainter weak halo in the diffraction pattern indicates that also an amorphous oxide has formed. The formation of an oxide becomes clearer after ion mixing at $570 \mathrm{~K}$ [fig. 1(b)]. The pictures taken at this temperature are representative for all $\mathrm{Ni}-\mathrm{Zr}$ samples irradiated between 370 and $620 \mathrm{~K}$. At these measurements the $\mathrm{Ni}-\mathrm{Zr}$ alloy is still amorphous, but also the metastable $\gamma-\mathrm{ZrO}_{2}$ phase [27] is observed. Note that no crystalline $\mathrm{Ni}-\mathrm{Zr}$ phases are observed, even though irradiations are performed at 

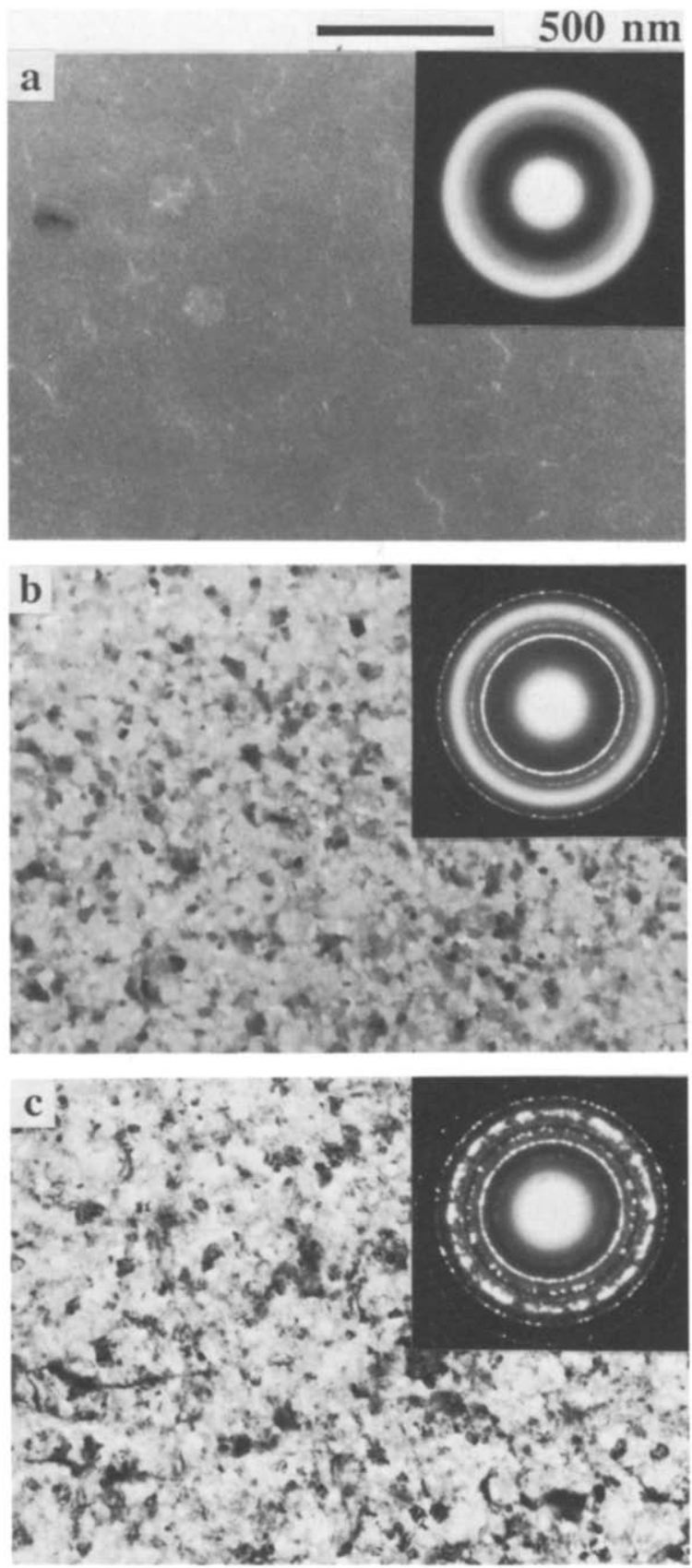

Fig. 1. Phase formation in amorphous $\mathrm{Ni}_{55} \mathrm{Zr}_{45}$ during ion beam mixing with $825 \mathrm{keV} \mathrm{Xe}{ }^{+}$ions to a dose of $1.5 \times 10^{15}$ ions $/ \mathrm{cm}^{2}$. TEM bright field images and diffraction patterns show that after irradiation: (a) at room temperature the alloy is amorphous; (b) after irradiation between 370 and $620 \mathrm{~K}$ amorphous $\mathrm{Ni}-\mathrm{Zr}$ and $\gamma-\mathrm{ZrO}_{2}$ are observed; the measurement is taken of a sample after irradiation at $570 \mathrm{~K}$; (c) after irradiation at temperatures of $650 \mathrm{~K}$ or higher the amorphous alloy has crystallized into the equilibrium compounds $\mathrm{Ni}_{2} \mathrm{Zr}$ and $\mathrm{Ni}_{5} \mathrm{Zr}$. Also $\gamma-\mathrm{ZrO}_{2}$ is observed; the measurement is taken after ion irradiation at $650 \mathrm{~K}$. temperatures far in the regime of RED, which sets in at $T_{\mathrm{c}} \approx 460 \mathrm{~K}$ [14]. During ion mixing at $650 \mathrm{~K}$ [fig. 1(c)] and higher temperatures crystallization into $\mathrm{Ni}_{2} \mathrm{Zr}$ and $\mathrm{Ni}_{5} \mathrm{Zr}$ intermetallic compounds [28] occurred. In addition the $\gamma-\mathrm{ZrO}_{2}$ phase is observed. For $T_{\mathrm{eq}}$ we took a value of $650 \mathrm{~K}$. The crystallization temperature of amorphous $\mathrm{Ni}_{55} \mathrm{Zr}_{45}$ is considerably lowered by ion irradiation. Only at $770 \mathrm{~K}$ the reference samples, which were only subjected to thermal treatment, crystallized into the intermetallics $\mathrm{Ni}_{2} \mathrm{Zr}$ and $\mathrm{Ni}_{10} \mathrm{Zr}_{7}$ [28]. At this temperature also diffraction lines of $\gamma-\mathrm{ZrO}_{2}$ are observed. The crystallization data of the thermally treated $\mathrm{Ni}-\mathrm{Zr}$ alloys agree well with literature data $[19,20]$. Note that the equilibrium phases formed by thermal annealing are slightly different from those formed during ion irradiation, probably because of small composition changes during oxidation.

Although a rather strong oxidation is observed, we believe that the effects on the crystallization process are small. It has been shown for several amorphous alloys that oxygen contamination strongly enhances the thermal stability [29]. However, oxidation during ion mixing of $\mathrm{Fe}-\mathrm{Zr}$ at elevated temperatures has also been observed by Bottiger et al. [30], who showed that the oxidation effects were restricted to the sample surface. Surface oxidation of $\mathrm{Ni}-\mathrm{Zr}$ alloys has been observed during thermal annealing in oxygen ambient [31,32]. The effect of surface oxidation is the formation of stoichiometric $\mathrm{Zr}$-oxides at the sample surface. As a consequence the underlying alloy slightly changes composition but its thermal stability is not affected.

The TEM micrographs of the amorphous $\mathrm{Fe}_{55} \mathrm{Zr}_{45}$ alloy in fig. 2 show similarity with the $\mathrm{Ni}-\mathrm{Zr}$ system. After ion irradiation between room temperature and $670 \mathrm{~K}$ [figs. 2(a) and 2(b)] amorphous $\mathrm{Fe}-\mathrm{Zr}$ and $\gamma-\mathrm{ZrO}_{2}$ are identified. Electron microprobe analysis showed that the oxygen content of both the irradiated and annealed samples increased to roughly 10 at $\%$. In reference samples, annealed at the same temperature, no diffraction lines of $\gamma-\mathrm{ZrO}_{2}$ are observed with TEM, probably because the oxide formed is amorphous whereas during ion irradiation the crystalline phase $\gamma-\mathrm{ZrO}_{2}$ appears. Primary crystallization of the amorphous $\mathrm{Fe}-\mathrm{Zr}$ phase occurs at approximately $720 \mathrm{~K}$ into the tetragonal $\mathrm{Fe}_{2} \mathrm{Zr}$ compound [33] during ion irradiation, as can be seen from fig. 2(c). The same crystallization process is observed in the reference samples after annealing at 870 $\mathrm{K}$, in agreement with literature data [21,22]. No crystalline phases are detected below the crystallization temperature during thermal annealing. Like $\mathrm{Ni}-\mathrm{Zr}$, also $\mathrm{Fe}-\mathrm{Zr}$ remains amorphous under influence of the ion beam up to temperatures far above $T_{c}$, which is approximately $480 \mathrm{~K}[15]$.

As can be seen in fig. 3, the same type of behavior is also observed for the $\mathrm{Au}-\mathrm{Zr}$ system. Results are shown for the amorphous $\mathrm{Au}_{50} \mathrm{Zr}_{50}$ alloy after irradiation at 

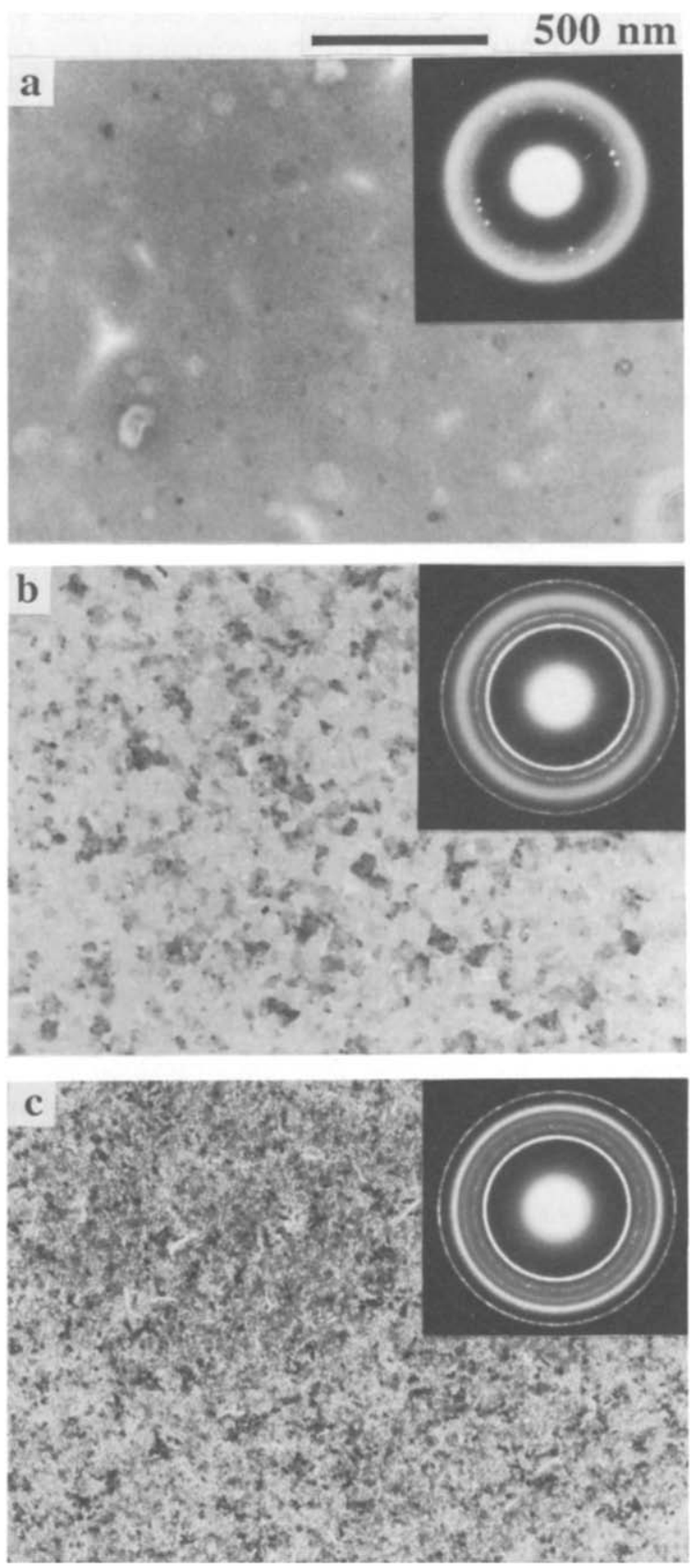

Fig. 2. Phase formation in amorphous $\mathrm{Fe}_{55} \mathrm{Zr}_{45}$ during ion beam mixing with $825 \mathrm{keV} \mathrm{Xe}{ }^{+}$ions to a dose of $1.5 \times 10^{15}$ ions $/ \mathrm{cm}^{2}$. TEM bright field images and diffraction patterns show that after irradiation: (a) at room temperature amorphous $\mathrm{Fe}-\mathrm{Zr}$ and some $\gamma-\mathrm{ZrO}_{2}$ is observed; (b) after ion mixing up to temperatures of $670 \mathrm{~K}$ amorphous $\mathrm{Fe}-\mathrm{Zr}$ is observed and $\gamma-\mathrm{ZrO}_{2}$ has formed; the pictures are from a sample irradiated at $670 \mathrm{~K} ;(\mathrm{c})$ at temperatures of $720 \mathrm{~K}$ and higher hexagonal $\mathrm{Fe}_{2} \mathrm{Zr}$ and $\gamma-\mathrm{ZrO}_{2}$ have formed; the measurement is from a sample irradiated at $720 \mathrm{~K}$.
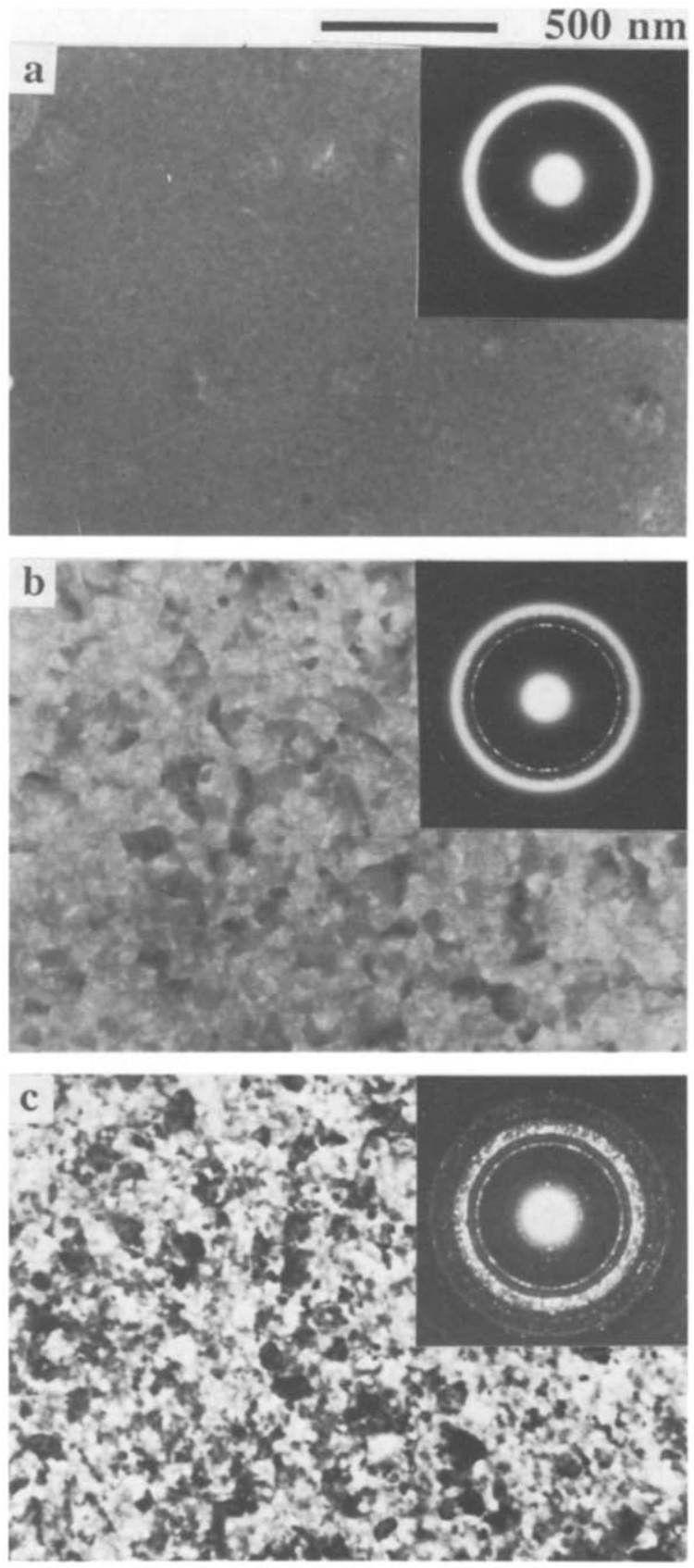

Fig. 3. Phase formation in amorphous $A u_{50} \mathrm{Zr}_{50}$ during ion beam mixing with $825 \mathrm{keV} \mathrm{Xe}{ }^{+}$ions to a dose of $1.5 \times 10^{15}$ ions $/ \mathrm{cm}^{2}$. TEM bright field images and diffaction patterns show that after irradiation: (a) at room temperature the $\mathrm{Au}-\mathrm{Zr}$ is still amorphous and some $\gamma-\mathrm{ZrO}_{2}$ has formed; (b) after irradiations between 370 and $570 \mathrm{~K}$ amorphous $\mathrm{Au}-\mathrm{Zr}$ and $\gamma-\mathrm{ZrO}_{2}$ are observed (pictures taken after irradiation at $570 \mathrm{~K}$ ), whereas (c) after ion irradiation at $620 \mathrm{~K}$ and higher the amorphous alloy has crystallized into an unidentified $\mathrm{Au}-\mathrm{Zr}$ phase; also $\mathrm{\gamma}^{-\mathrm{ZrO}_{2}}$ is observed. 
room temperature, $570 \mathrm{~K}$, and $620 \mathrm{~K}$ respectively. Up to $570 \mathrm{~K}$ only amorphous $\mathrm{Au}-\mathrm{Zr}$ and $\gamma-\mathrm{ZrO}_{2}$ are observed, whereas at temperatures of $620 \mathrm{~K}$ and higher crystallization into an unidentified phase occurs. Thermal annealing without ion irradiation leads to crystallization at $720 \mathrm{~K}$ into the same unidentified phase. In a second set of samples with a composition of $\mathrm{Au}_{35} \mathrm{Zr}_{65}$, crystallization into the $\mathrm{Au}_{4} \mathrm{Zr}$ equilibrium phase [34] is observed to occur at $670 \mathrm{~K}$ during ion irradiation, and at $770 \mathrm{~K}$ during thermal annealing. Also amorphous $\mathrm{Au}-\mathrm{Zr}$ is found to be stable under ion irradiation far above the critical temperature for RED, which is $T_{c} \approx$ $450 \mathrm{~K}[16]$.

\section{2. $P d-T a$}

A summary of the results of ion mixing of the Pd-Ta bilayers is presented in fig. 4 , where the squares of the normalized diffusion distances, $(\Delta x)^{2}$, are plotted in Arrhenius fashion. The mixing experiments were performed with $825 \mathrm{keV}{ }^{129} \mathrm{Xe}^{+}$ions with fluences varying between $0.4 \times 10^{15}$ and $5.0 \times 10^{15}$ ions $/ \mathrm{cm}^{2}$. The thickness $\Delta x$ of the intermixed layer is inferred from RBS spectra (not shown). $\Delta x$ is determined as the thickness between heights of $16 \%$ and $84 \%$ of the gradually changing concentration profile due to intermixing at the interface. The data in fig. 4 are scaled to a dose of $1 \times 10^{15}$ ions $/ \mathrm{cm}^{2}$. As can be seen from fig. 4, the

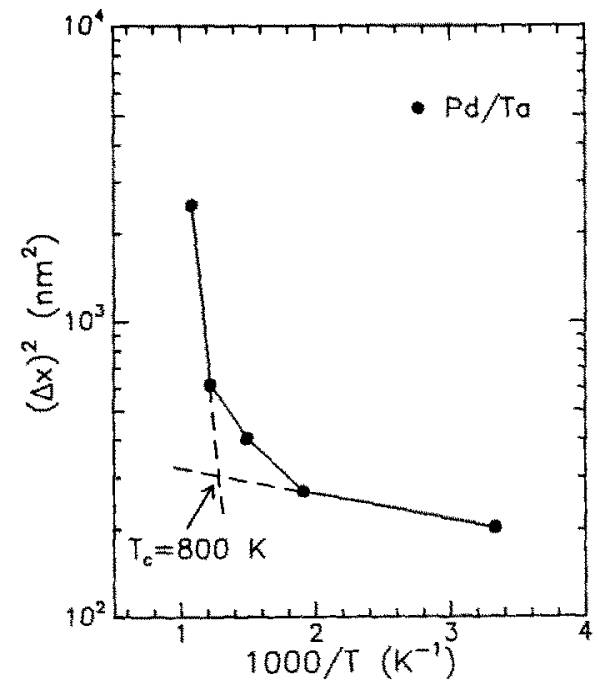

Fig. 4. The temperature dependence of ion beam mixing of a $\mathrm{Pd} / \mathrm{Ta}$ bilayer with $825 \mathrm{keV} \mathrm{Xe} \mathrm{e}^{*}$ ions. The thickness $\Delta x$ of the intermixed layer is scaled to a dose of $1 \times 10^{15}$ ions $/ \mathrm{cm}^{2}$. At high temperatures the mixing behavior is strongly temperature dependent. The critical temperature for RED, $T_{c}=$ $800( \pm 75) \mathrm{K}$ is determined by the intercept of the extrapolated temperature-dependent and temperature-independent parts of the Arrhenius-curve. mixing behavior is almost temperature independent at low temperatures, whereas at high temperatures $(T>800$ $\mathrm{K})$ a strong temperature dependence is observed. The critical temperature for RED is taken as the intercept of the extrapolated temperature-dependent and temperature-independent contributions in the Arrhenius-curve of fig. 4. We find for ion beam mixing of $\mathrm{Pd} / \mathrm{Ta}$ bilayers that $T_{c} \approx 800 \mathrm{~K}( \pm 75 \mathrm{~K})$. After ion irradiation up to temperatures of $820 \mathrm{~K}$ the intermixed layer shows a gradual change in the concentration profile. After ion irradiation at $920 \mathrm{~K}$ and higher temperatures plateaus in the RBS spectra indicate phase formation.

Phase formation is studied in multilayer samples of elemental $\mathrm{Pd}$ and $\mathrm{Ta}$ with an overall composition of $\mathrm{Pd}_{40} \mathrm{Ta}_{60}$. The phase formation is shown in fig. 5 . In the as-deposited films (not shown) only the Pd and $\alpha$-Ta phases $[35,36]$ with a grain size less than $100 \AA$ are observed. After irradiation between room temperature and $520 \mathrm{~K}$, the film is completely amorphized for fluences higher than approximately $4 \times 10^{15}$ ions $/ \mathrm{cm}^{2}$ [fig. 5(a)]. At higher temperatures an amorphous alloy and a supersaturated solid solution of $\mathrm{Pd}(\mathrm{Ta})$ are formed. Fig. 5(b) shows such a sample after ion mixing at $670 \mathrm{~K}$. The Pd(Ta)-grains have sizes up to $400 \AA$ and the grain size increases to $600 \AA$ after irradiation at 820 K. Above this temperature not only metastable phases are formed, but also the equilibrium PdTa phase [36], see fig. $5(\mathrm{c})$. In none of the samples could significant changes in composition due to sputtering be observed with EDX analysis (energy dispersive X-ray absorption). Oxidation is not observed after ion irradiation up to temperatures of $1020 \mathrm{~K}$. Above this temperature some $\mathrm{Ta}_{2} \mathrm{O}_{5}$ [38] is observed together with the PdTa equilibrium phase. For the critical temperature for equilibrium phase formation in the Pd-Ta system we take $T_{\text {eq }}=820 \mathrm{~K}$.

Calculations according to Miedema's model [8] show that for the alloy $\operatorname{Pd}_{40} \mathrm{Ta}_{60}$, the composition we used, the supersaturated solid solution Pu(Ta) is thermodynamically the more favorable metastable phase compared to amorphous $\mathrm{Pd}_{40} \mathrm{Ta}_{60}$. However, in this work it has been found that multilayered $\mathrm{Pd} / \mathrm{Ta}$ is completely amorphized up to temperatures of $520 \mathrm{~K}$. Apparently the amorphous phase forms due to the high quench rate in the ion induced collision cascade. It can be seen from the Arrhenius-curve in fig. 4, that above $520 \mathrm{~K}$ the temperature-dependent mixing process becomes significant. According to our model Pd-atoms will become mobile first. This gives the system enough mobility to form the more favorable metastable solid solution $\mathrm{Pd}(\mathrm{Ta})$, but not enough to form equilibrium compounds. Nucleation of $\mathrm{Pd}(\mathrm{Ta}$ ) seems to be enhanced by the initially crystalline nature of the sample, for it has been shown elsewhere that after ion irradiation of (codeposited) amorphous $\mathrm{Pd}_{40} \mathrm{Ta}_{60}$ up to temperatures of $670 \mathrm{~K}$ no crystalline phases are detected [23]. In agree- 

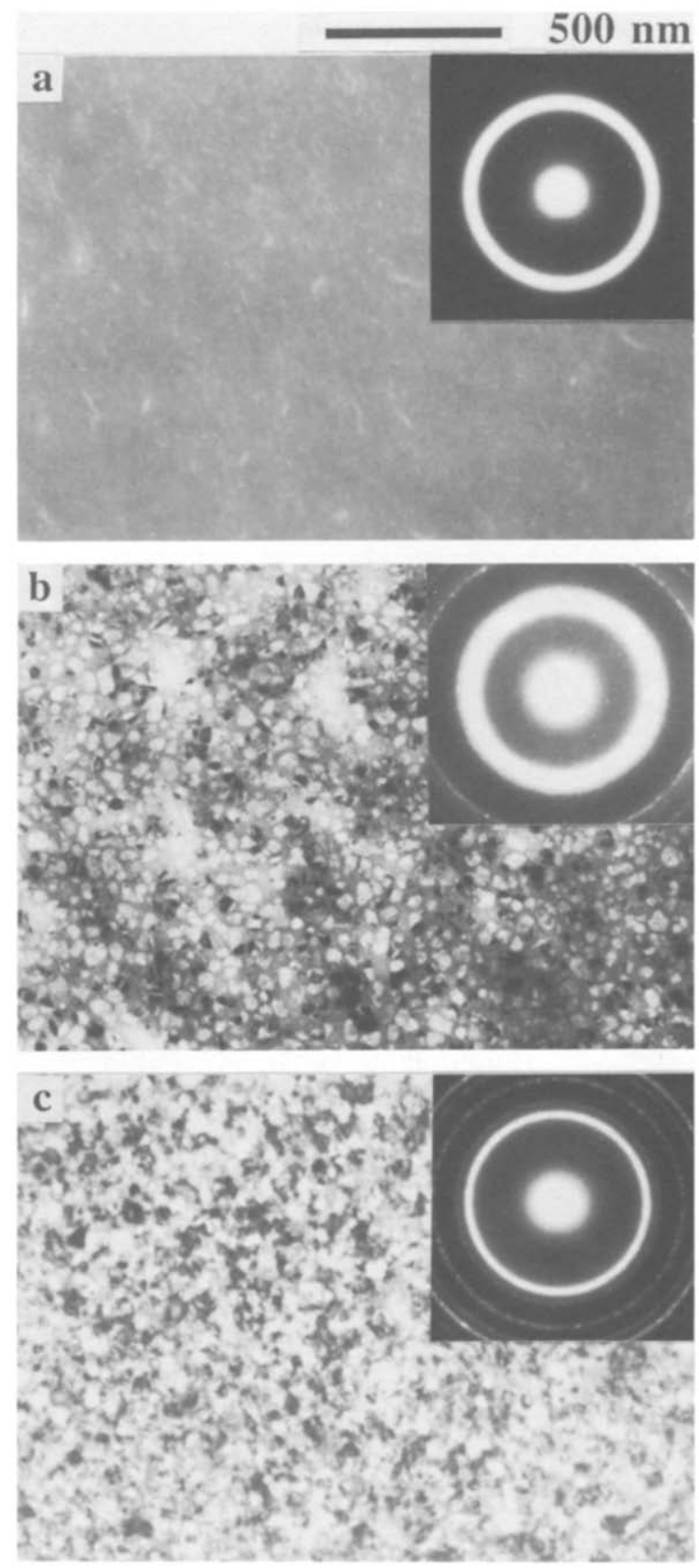

Fig. 5. TEM bright field images and diffraction patterns after ion beam mixing of $\mathrm{Pd} / \mathrm{Ta}$ multilayers with $825 \mathrm{keV} \mathrm{Xe}{ }^{+}$ins with doses in the order of $5 \times 10^{15}$ ions $/ \mathrm{cm}^{2}$. (a) During irradiation at temperatures below $520 \mathrm{~K}$ the initial crystalline sample has transformed into an amorphous alloy; shown is a sample after irradiation at room temperature; (b) at $670 \mathrm{~K}$ amorphous Pd-Ta and a supersaturated solid solution $\mathrm{Pd}(\mathrm{Ta})$ have formed; this observation is typical for samples irradiated between 570 and $720 \mathrm{~K}$; (c) at $820 \mathrm{~K}$ and higher the equilibrium phase PdTa is observed. ment with the Miedema model a slight change in composition results in amorphous $\mathrm{Pd}_{33} \mathrm{Ta}_{67}$ being the more stable phase compared to a solid solution at the same composition [8]. At this composition a (diffusionless) polymorphic transition from the amorphous phase to the solid solution is not possible and the amorphous alloy has been found to be stable against ion irradiation up to $870 \mathrm{~K}[23]$.

\section{Discussion}

The experimental results of this work are summarized in table 1. Values of $T_{c}$ for the $Z$ ralloys are taken from the literature [14-16]. The hole formation enthalpies. $\Delta H_{\mathrm{V}}$ for amorphous alloys $\mathrm{A}_{1-x} \mathrm{~B}_{x}$ are calculated according to Miedema's model [8] using the expressions:

$\Delta H_{\mathrm{V}}^{\mathrm{A}}=c_{\mathrm{A}} \Delta H_{1 \mathrm{~V}}^{\mathrm{A}}+\left(1-c_{\mathrm{A}}\right)\left(V_{\mathrm{A}} / V_{\mathrm{B}}\right)^{5 / 6} \Delta H_{1 \mathrm{~V}}^{\mathrm{B}}$

and

$\Delta H_{\mathrm{V}}^{\mathrm{B}}=c_{\mathrm{B}} \Delta H_{1 \mathrm{~V}}^{\mathrm{B}}+\left(1-c_{\mathrm{B}}\right)\left(V_{\mathrm{B}} / V_{\mathrm{A}}\right)^{5 / 6} \Delta H_{1 \mathrm{~V}}^{\mathrm{A}}$

$\Delta H_{1 \mathrm{~V}}^{\mathrm{A}}$ and $\Delta H_{1 \mathrm{~V}}^{\mathrm{B}}$ are the monovacancy formation enthalpies in pure $\mathrm{A}$ and $\mathrm{B}$. The molar volume ratios $\left(V_{\mathrm{A}} / V_{\mathrm{B}}\right)$ can be regarded as a measure to which degree atoms are surrounded by both constituents and the effective (surface) concentrations $c_{A}$ and $c_{B}$ depend on $x$. The accuracy of $\Delta H_{1 \mathrm{~A}}^{\mathrm{A}}$ and $\Delta H_{\mathrm{lv}}^{\mathrm{B}}$ is estimated to be within $5 \%$. The data of table 1 are visualized in fig. 6 , wherein $T_{\mathrm{c}}$ is plotted versus $\Delta H_{\mathrm{v}_{\mathrm{small}}}$ (open symbols) and $T_{\text {eq }}$ versus $\Delta H_{\text {Vlarge (closed symbols). A linear }}$ relationship between hole formation enthalpies and the critical temperatures $T_{c}$ and $T_{\text {eq }}$ is indicated (the dashed line is drawn to guide the eye). Remarkable is the fact that where the difference in whole formation enthalpies $\left(\Delta H_{\text {Vlarge }}-\Delta H_{\text {vsmall }}\right)$ is large, the difference between $T_{\text {eq }}$ and $T_{\mathrm{c}}$ is large. This is the case for the $\mathrm{Zr}$-alloys. In the $\mathrm{Pd}-\mathrm{Ta}$ system this difference is not so pronounced and $T_{\mathrm{c}}$ and $T_{\mathrm{eq}}$ have the same values within the error bars.

Table 1

Experimental results of this work. Critical temperatures for RED for the $\mathrm{Zr}$-alloys are obtained from the literature [14-16]. Hole formation enthalpies are calculated using relations (1) and (2).

\begin{tabular}{lllll}
\hline Alloy & $\begin{array}{l}T_{\mathrm{c}} \\
(\mathrm{K})\end{array}$ & $\begin{array}{l}T_{\mathrm{eq}} \\
(\mathrm{k})\end{array}$ & $\begin{array}{l}\Delta H_{\text {vsmall }} \\
(\mathrm{kJ} / \text { mole })\end{array}$ & $\begin{array}{l}\Delta H_{\text {Vlarge }} \\
(\mathrm{kJ} / \text { mole })\end{array}$ \\
\hline $\mathrm{Ni}_{55} \mathrm{Zr}_{45}$ & 460 & 650 & $110(\mathrm{Ni})$ & $193(\mathrm{Zr})$ \\
$\mathrm{Fe}_{55} \mathrm{Zr}_{45}$ & 480 & 720 & $117(\mathrm{Fe})$ & $196(\mathrm{Zr})$ \\
$\mathrm{Au}_{50} \mathrm{Zr}_{50}$ & 450 & 620 & $126(\mathrm{Au})$ & $149(\mathrm{Zr})$ \\
$\mathrm{Au}_{35} \mathrm{Zr}_{65}$ & & 670 & $134(\mathrm{Au})$ & $156(\mathrm{Zr})$ \\
$\mathrm{Pd}_{40} \mathrm{Ta}_{60}$ & 800 & 820 & $171(\mathrm{Pd})$ & $191(\mathrm{Ta})$ \\
\hline
\end{tabular}




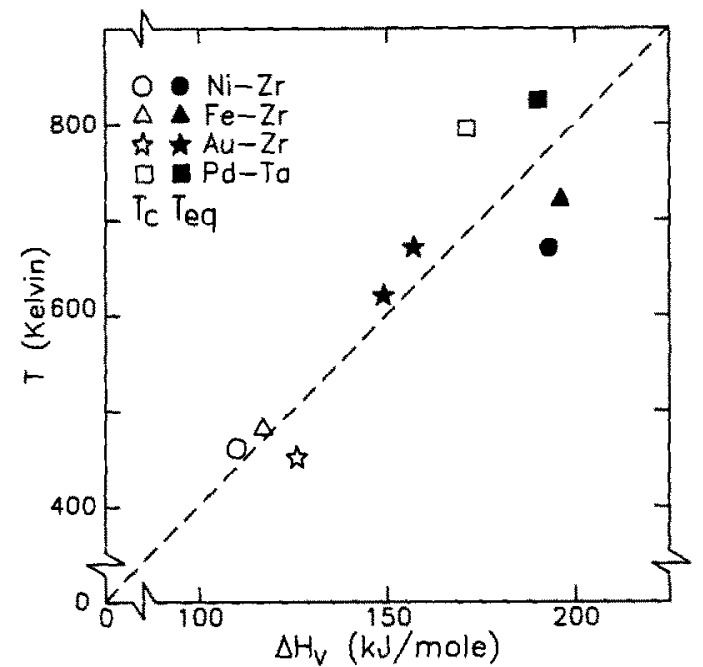

Fig. 6. Summary of the results presented in table 1. Plotted are the critical temperatures for temperature dependent diffusion, $T_{\mathrm{c}}$, versus formation enthalpies of holes the size of the smaller constituent, $\Delta H_{\mathrm{V}_{\text {small }}}$ (open symbols), and the critical temperatures for equilibrium phase formation, $T_{\mathrm{eq}}$, versus formation enthalpies of holes the size of the larger constituent, $\Delta H_{\text {Vlarge }}$ (closed symbols). $T_{\text {eq }}$ values for Au- $\mathrm{Zr}$ represent two different compositions. The dashed line $T=4 \times \Delta H_{\mathrm{V}}$ is drawn to guide the eye.

To support our model for two critical temperatures in ion beam mixing, more data have been collected. In tablc 2 a compilation of data from literature on $T_{\mathrm{c}}$ and $T_{\mathrm{eq}}$ is given for 30 systems. For the aluminides $\mathrm{Al}-\mathrm{Fe}$, $\mathrm{Al}-\mathrm{V}$, and $\mathrm{Al}-\mathrm{Zr}, \mathrm{T}_{\mathrm{eq}}$ is not known, but instead we have taken published temperatures at which quasicrystals form during ion beam mixing. Also in table 2 hole formation enthalpies are given. Values for $\Delta H$ were calculated by means of the expressions (1) and (2) for disordered systems at equiatomic composition. The equiatomic composition was chosen because in many of the experiments results were obtained on bilayer systems or structures consisting of single overlayers on thick substrates for which the final composition is not fixed.

In fig. 7 the values given in table 2 for $T_{\mathrm{c}}$ are plotted versus $\Delta H_{\mathrm{v} \text { small }}$. Indeed a linear relationship is observed. The scatter in the datapoints amounts to $75 \mathrm{~K}$. A least-squares fit to all datapoints yields:

$T_{\mathrm{c}}=4.0( \pm 0.2) \times \Delta H_{\mathrm{vsmall}}$

in which $T_{c}$ is given in kelvin and $\Delta H_{V_{s m a l l}}$ in $\mathrm{kJ}$ per mole.

The relationship between $T_{\text {ea }}$, with errors up to $50 \mathrm{~K}$, and $\Delta H_{\text {Vlarge }}$ can be seen in fig. 8 ,

$T_{\text {eq }}=3.8( \pm 0.2) \times \Delta H_{\text {Vlarge }}$

is found. Using the relationships (3) and (4) in combina-

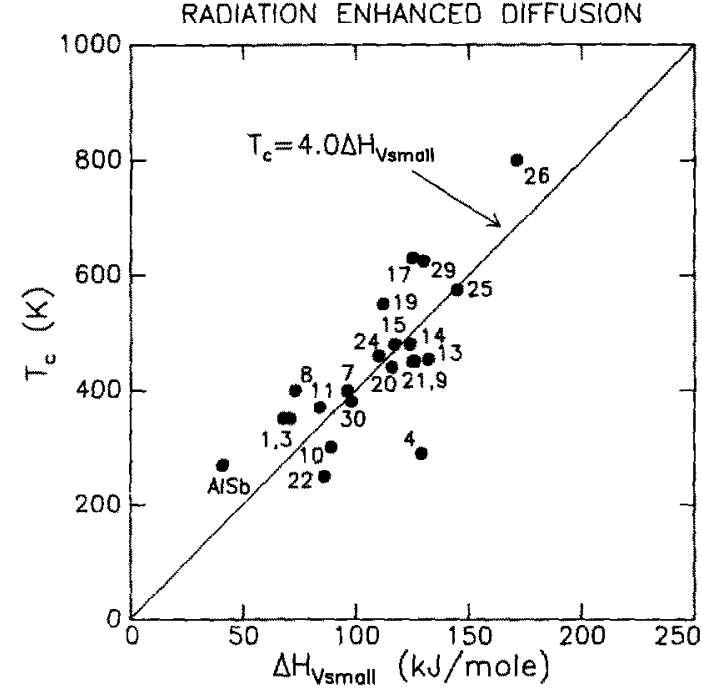

Fig. 7. Onset temperatures for radiation enhanced diffusion, $T_{c}$, versus formation enthalpy of holes the size of the smaller constituent, $\Delta H_{\mathrm{V}_{\mathrm{small}}}$, for several systems reported in the literature. The maximum error in $T_{\mathrm{c}}$ is $75 \mathrm{~K}$. The source of the datapoints is given by the running numbers that correspond to the first column in table 2. Also included is the non-metallic system Al-Sb (Ref. [76]; $T_{\mathrm{c}} \approx 270 \mathrm{~K}$ ). The line $T_{\mathrm{c}}=4.0 \times$ $\Delta H_{v_{\text {small }}}$ is a least-squares fit to the datapoints compilated in table 2.

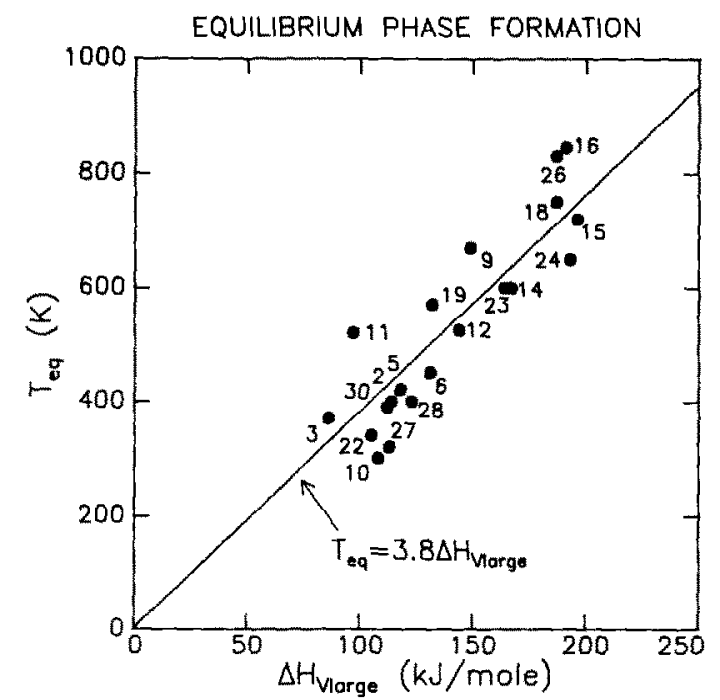

Fig. 8. Critical temperatures, $T_{\text {eq }}$, above which equilibrium phases will be formed during ion beam mixing versus formation enthalpy of holes the size of the larger constituent, $\Delta H_{\text {Vlarge }}$ for several systems reported in literature. The maximum error in $T_{\mathrm{eq}}$ is $50 \mathrm{~K}$. The source of the datapoints is given by the nunning numbers that correspond to the first column in table 2 . The line $T_{\text {eq }}=3.8 \times \Delta H_{\text {Vlarge }}$ is a least-squares fit to the datapoints. 
Table 2

Literature overview of critical temperatures for radiation enhanced diffusion $\left(T_{c}\right)$ and metastable alloy formation ( $T_{\mathrm{eq}}$ ). Hole formation enthalpies are calculated at equiatomic composition for random alloys according to the Miedema model [8] using relations (1) and (2). All systems have negative or near zero heat of mixing. The numbering of the alloys corresponds with the numbering of the datapoints in fig. 7 and 8.

\begin{tabular}{|c|c|c|c|c|c|c|c|}
\hline Alloy & & $\begin{array}{r}T_{\mathrm{c}} \\
(\mathbf{K})\end{array}$ & Refs. & $\begin{array}{l}T_{\mathrm{eq}} \\
(\mathrm{K})\end{array}$ & Refs. & $\begin{array}{l}\Delta H_{\mathrm{V}_{\text {small }}} \\
(\mathrm{kJ} / \mathrm{mole})\end{array}$ & $\begin{array}{l}\Delta H_{\text {Vlarge }} \\
(\mathrm{kJ} / \text { mole })\end{array}$ \\
\hline 1 & $\mathrm{Al}-\mathrm{Cu}$ & 350 & {$[45]$} & - & - & $71(\overline{\mathrm{Cu}})$ & $93(\mathrm{Al})$ \\
\hline 2 & $\mathrm{Al}-\mathrm{Fe}$ & - & - & 400 & {$[46,47]$} & $89(\mathrm{Fe})$ & $114(\mathrm{Al})$ \\
\hline 3 & Al-Mn & 350 & {$[48]$} & 370 & {$[48,49,50,51]$} & $68(\mathrm{Mn})$ & $86(\mathrm{Al})$ \\
\hline 4 & Al-Mo & 290 & [52] & - & - & $129(\mathrm{Mo})$ & $132(\mathrm{Al})$ \\
\hline 5 & $A l-V$ & - & -. & 420 & [53] & $102(\mathrm{~V})$ & $118(\mathrm{Al})$ \\
\hline 6 & $\mathrm{Al}-\mathrm{Zr}$ & - & - & 450 & {$[47,54]$} & $103(\mathrm{Al})$ & $131(\mathrm{Zr})$ \\
\hline 7 & $\mathrm{Au}-\mathrm{Ni}$ & 400 & {$[55]$} & - & - & $96(\mathrm{Ni})$ & $137(\mathrm{Au})$ \\
\hline 8 & $\mathrm{Au}-\mathrm{Si}$ & 400 & {$[56,57]$} & - & - & $73(\mathrm{Si})$ & $86(\mathrm{Au})$ \\
\hline 9 & $\mathrm{Au}-\mathrm{Zr}$ & 450 & [16] & 620 & this work & $126(\mathrm{Au})$ & $149(\mathrm{Zr})$ \\
\hline 10 & $\mathrm{Co}-\mathrm{Si}$ & 300 & [58] & 300 & [58] & $89(\mathrm{Co})$ & 108 (Si) \\
\hline 11 & $\mathrm{Cr}-\mathrm{Si}$ & 370 & {$[59]$} & 520 & [59] & $84(\mathrm{Cr})$ & $97(\mathrm{Si})$ \\
\hline 12 & $\mathrm{Cu}-\mathrm{Ti}$ & - & - & 525 & {$[60,61,62]$} & $107(\mathrm{Cu})$ & $144(\mathrm{Ti})$ \\
\hline 13 & $\mathrm{Fe}-\mathrm{Pt}$ & 454 & {$[63]$} & - & - & $132(\mathrm{Fe})$ & $168(\mathrm{Pt})$ \\
\hline 14 & $\mathrm{Fe}-\mathrm{Ti}$ & 480 & {$[64]$} & 600 & {$[64]$} & $124(\mathrm{Fe})$ & $167(\mathrm{Ti})$ \\
\hline 15 & $\mathrm{Fe}-\mathrm{Zr}$ & 480 & {$[15]$} & 720 & this work & $117(\mathrm{Fe})$ & $196(\mathrm{Zr})$ \\
\hline 16 & $\mathrm{Mo}-\mathrm{Ni}$ & - & - & 830 & {$[65]$} & $143(\mathrm{Ni})$ & 187 (Mo) \\
\hline 17 & Mo-Si & 630 & {$[66,67]$} & - & - & $125(\mathrm{Si})$ & $134(\mathrm{Mo})$ \\
\hline 18 & $\mathrm{Nb}-\mathrm{Ni}$ & - & - & 750 & {$[18]$} & $129(\mathrm{Ni})$ & $187(\mathrm{Nb})$ \\
\hline 19 & $\mathrm{Nb}-\mathrm{Si}$ & 550 & [1] & 570 & [1] & $112(\mathrm{Si})$ & $132(\mathrm{Nb})$ \\
\hline 20 & $\mathrm{Ni}-\mathrm{Pd}$ & 440 & {$[63,68]$} & - & - & $116(\mathrm{Ni})$ & $150(\mathrm{Pd})$ \\
\hline 21 & $\mathrm{Ni}-\mathrm{Pt}$ & 450 & {$[55]$} & - & - & $125(\mathrm{Ni})$ & $166(\mathrm{Pt})$ \\
\hline 22 & $\mathrm{Ni}-\mathrm{Si}$ & 250 & [69] & 340 & {$[59,70,71]$} & $86(\mathrm{Ni})$ & $105(\mathrm{Si})$ \\
\hline 23 & $\mathrm{Ni}-\mathrm{Ti}$ & - & - & 600 & {$[18,65]$} & $117(\mathrm{Ni})$ & $164(\mathrm{Ti})$ \\
\hline 24 & $\mathrm{Ni}-\mathrm{Zr}$ & 460 & {$[14]$} & 650 & this work & $110(\mathrm{Ni})$ & $193(\mathrm{Zr})$ \\
\hline 25 & $\mathrm{Pd}-\mathrm{Pt}$ & 575 & {$[10]$} & - & - & $145(\mathrm{Pd})$ & $149(\mathrm{Pt})$ \\
\hline 26 & $\mathrm{Pd}-\mathrm{Ta}$ & 800 & this work & 820 & this work, $[23]$ & $171(\mathrm{Pd})$ & 191 (Ta) \\
\hline 27 & $\mathrm{Pt}-\mathrm{Si}$ & - & - & 320 & {$[59,71]$} & $104(\mathrm{Si})$ & $113(\mathrm{Pt})$ \\
\hline 28 & $\mathrm{Ru}-\mathrm{Si}$ & - & - & 400 & {$[72]$} & $121(\mathrm{Ru})$ & $123(\mathrm{Si})$ \\
\hline 29 & $\mathrm{Si}-\mathrm{Ta}$ & 625 & {$[11]$} & - & - & $130(\mathrm{Si})$ & $154(\mathrm{Ta})$ \\
\hline 30 & $\mathrm{Si}-\mathrm{Ti}$ & 380 & {$[73,74,75]$} & 390 & {$[74]$} & $98(\mathrm{Si})$ & $112(\mathrm{Ti})$ \\
\hline
\end{tabular}

tion with the expressions (1) and (2) to calculate the hole formation enthalpies, it is possible to predict temperature ranges in which fast mixing occurs via RED, and yet metastable alloys are formed.

Our results show the existence of two critical temperatures in ion beam mixing. Both temperatures are correlated with hole formation enthalpies. This may be understood as follows. The interdiffusion coefficient for RED is given by the relation:

$\tilde{D} \propto\left(X_{\mathrm{B}} D_{\mathrm{A}}+X_{\mathrm{A}} D_{\mathrm{B}}\right)$.

$X_{\mathrm{A}}$ and $X_{\mathrm{B}}$ are the mole fractions of element $\mathrm{A}$ and $\mathrm{B}$. $D_{\mathrm{A}}$ and $D_{\mathrm{B}}$ are the self-diffusion coefficients for RED, which can be written in the form:

$D_{i}=D_{i, 0} \exp \left(-Q_{i} / k T\right)$.
The corresponding activation energies $Q_{\mathrm{A}}$ and $Q_{\mathrm{B}}$ are given by $\Delta H_{\mathrm{MA}}$ and $\Delta H_{\mathrm{MB}}$, the migration enthalpies for $A$ and $B$ atoms respectively. Because not much is known about migration enthalpies in amorphous alloys, we approximate $\Delta H_{\mathrm{MA}}$ and $\Delta H_{\mathrm{MB}}$ by the hole formation enthalpies $\Delta H_{\mathrm{VA}}$ and $\Delta H_{\mathrm{VB}}$, which are calculated using the expressions (1) and (2). The replacement of migration enthalpies by hole formation enthalpies is based on the following. In an excellent review by Brown and Ashby [39] it has been shown clearly that the ratio $Q_{\mathrm{SD}} / R T_{\mathrm{m}}$ ( $Q_{\mathrm{SD}}$ is the activation cnergy for substitutional diffusion and $T_{\mathrm{m}}$ is the melting point) is constant over a wide range of systems. Together with the wellknown observation that $\Delta H_{\mathrm{V}}$ scales with $T_{\mathrm{m}}$ [40], it can be easily derived that $\Delta H_{\mathrm{V}}$ is proportional to $\Delta H_{\mathrm{M}}$. If 
both $Q_{\mathrm{SD}}$, which is $\Delta H_{\mathrm{Y}}+\Delta H_{\mathrm{M}}$, and $\Delta H_{\mathrm{V}}$ are proportional to $T_{\mathrm{m}}, \Delta H_{\mathrm{M}}$ must be proportional to $\Delta H_{\mathrm{V}}$. Moreover, observations by Shewmon [41] and more recently by Franklin [42], showed for several metals that $\Delta H_{\mathrm{M}}$ and $\Delta H_{\mathrm{V}}$ are equal within $10 \%$ accuracy.

The linear relationships (3) and (4) indicate that in ion beam mixing the apparent activation energies of the temperature-dependent diffusion processes are the determining factors for the related critical temperatures. The preexponential factors for the self-diffusion coefficients, which will depend on the system studied and the particular experimental conditions, seem to be of less importance. This has also been shown by Rauschenbach [43], who found a dependence of $T_{c}$ on $\Delta H_{\mathrm{V}}^{\mathrm{m}}$, the average migration enthalpy of vacancies. So, assuming a constant $D_{i, 0}$ for each system, and equal for atoms $A$ and $\mathrm{B}, D_{i}$ will depend critically on the ratio $\left(\Delta H_{\mathrm{v}} / k T\right)$, resulting in the linear relationships (3) and (4) between temperature and hole formation enthalpy.

The predictions for $T_{\mathrm{c}}$ and $T_{\mathrm{eq}}$ should not be regarded as absolute values but rather as estimates, as can be seen by the deviations from the model up to $100 \mathrm{~K}$ in figs. 7 and 8 . Furthermore, important parameters, such as the nucleation and growth mechanisms are ignored in the present model. Note that in some cases above $T_{\mathrm{c}}$ a metastable crystalline phase nucleates first. Then there must be still a higher temperature at which equilibrium is truly achieved. Detalled information about the processes involved can only be obtained by studying individual systems. For example, the complexity of ion induced diffusion processes in elementary $\mathrm{Ni}$ is demonstrated by Müller et al. [44]. Nonetheless, from their data a $T_{\varepsilon}$ of $600 \mathrm{~K}$ can be inferred, a value which is still within the predicted range of $525( \pm 75) \mathrm{K}$ of our model.

Although different criteria are applied to determine $T_{\mathrm{c}}$ and $T_{\mathrm{eq}}$, it is possible to compare the proportionality constants $C_{\mathrm{c}}=4.0( \pm 0.2)$ and $C_{\mathrm{eq}}=3.8( \pm 0.2)$ from relations (3) and (4). Because the measured effects (diffusion cq. crystallization) are on comparable length and time scales (in the order of $100 \AA$ and $1 \mathrm{~h}$ respectively) we expect $C_{\mathrm{c}}$ and $C_{\mathrm{eq}}$ to be approximately the same. Within the error bars this is indeed the case. It should be mentioned that for individual systems the preexponential factors for the self-diffusion coefficients (5) will depend on experimental conditions and a dose rate dependence might be expected for both $T_{\mathrm{c}}$ and $T_{\mathrm{eq}}$.

Previous investigations have shown that for the crystallization temperature, $T_{x}$, for amorphous alloys via a diffusion controlled process the following relationship holds [17,77]:

$T_{\mathrm{x}} \approx 4.7 \times \Delta H_{\text {vlarge }}$.

In the model that is put forwatd in these papers crystallization is governed by diffusivity of the larger constituent. The self-diffusion coefficient for this constituent will have the same form as (5) and the corre- sponding activation energy will be $Q_{x}$. Because for the determination of $T_{\mathrm{x}}$ and $T_{\mathrm{eq}}$ the same effect is investigated (growth of crystals larger than $100 \AA$ on time scales of typically $1 \mathrm{~h}$ ) a direct comparison can be made of the activation energies for thermal and ion induced crystallization of amorphous alloys under the assumption that the pre-exponential factors for both diffusion processes are approximately equal. As argued before, a linear relationship between crystallization temperature and hole formation enthalpy indicates that the activation energy is most important. It then can be derived that the ratio of the activation energies equals the ratio of the proportionality constants from eqs. (4) and (6):

$Q_{\aleph} / Q_{\text {eq }}=C_{x} / C_{\mathrm{eq}} \approx 1.2$,

wherein the activation energy for the ion-induced crystallization process is labeled $Q_{\mathrm{eq}}$. The relative difference between $Q_{\mathrm{x}}$ and $Q_{\mathrm{sq}}$ is unexpectedly small and might be influenced by the inaccuracy of the proportionality constants $C_{\mathrm{x}}$ and $C_{\mathrm{eq}}$. A larger difference is expected when the activation energy of the ion induced process is considered as a migration enthalpy only, and the activation energy of the thermal process as the same migration enthalpy plus an additional energy associated with the creation of holes or vacancies required for vacancy* like diffusion in amorphous alloys. This clearly requires further investigation.

\section{Conclusions}

Ion mixing with high energy heavy ions has been shown to lower the crystallization temperature of the amorphous alloys $\mathrm{Ni}-\mathrm{Zr}, \mathrm{Fe}-\mathrm{Zr}, \mathrm{Au}-\mathrm{Zr}$, and $\mathrm{Pd}-\mathrm{Ta}$ significantly. Furthermore, it has been shown that in ion beam mixing of binary systems two critical temperatures can be defined. These temperatures can be predicted by the expressions:

$T_{\mathrm{c}} \approx 4.0 \times \Delta H_{\text {Vsmail }}$

and

$T_{\text {eq }}=3.8 \times \Delta H_{\text {Vlarge }}$,

in which the temperatures are given in kelvin and the hole formation enthalpies in $\mathrm{kJ} /$ mole. At $T_{c}$ the smaller consiituent becomes mobile and RED sets in. However, metastable phases will form and remain stable under influence of the ion beam below $T_{\text {eq. }}$. Above this temperature also the larger constituent can migrate over large distances and equilibrium phases will form. For systems with a large difference between hole formation enthalpies $\Delta H_{\text {Vlarge }}-\Delta H_{\mathrm{V}_{\text {small }}}$ metastable alloys can be formed rather efficiently using RED. The values for $T_{c}$ and $T_{\text {eq }}$ as predicted with our model should not be regarded as absolute values but rather as guidelines to 
select systems in which phenomena as RED and metastable alloy formation occur simultaneously.

\section{Acknowledgments}

The authors would like to thank R.J.I.M. Koper and H. Zeijlemaker for assistance with the depositions and R.J. Schreutelkamp and J.R. Liefting for assistance with the irradiations. Furthermore, we would like to acknowledge J. Hengst of Philips Research Laboratories in Eindhoven for electron microprobe analysis of the $\mathrm{Fe}-\mathrm{Zr}$ samples and Dr. A Knoester of Shell Research Laboratories in Amsterdam for EDX analysis. We are obliged to Dr. H. Bakker of Het Natuurkundig Laboratorium der Universiteit van Amsterdam for helpful discussions. This work is part of the research program of the Stichting for Fundamenteel Onderzoek der Materie (Foundation for Fundamental Research on Mattcr) and was financially supported by the Nederlandse Organisatie voor Wetenschappelijk Onderzoek (Netherlands Organization for Scientific Research) and the Stichting Technische Wetenschappen (Netherlands Technology Foundation).

\section{References}

[1] S. Matteson, J. Roth, and M.-A. Nicolet, Radiat. Eff. 42 (1979) 217.

[2] R.S. Averback, Nucl. Instr. and Meth. B15 (1986) 675.

[3] Surface Alloying by Ion, Electron, and Laser Beams, eds. L.E. Rehn, S.T. Picraux, and H. Wiedersich, (American Society for Metals, Metals Park, Ohio 1987).

[4] M. van Rossum and Y.-T. Cheng, Defect and Diffusion Forum 57-58 (1988) 1.

[5] L.E. Rehn and P.R. Okamoto, Nucl. Instr. and Meth. B39 (1989) 104.

[6] W.L. Johnson, Y.-T. Cheng, M. van Rossum, and M-A. Nicolet, Nucl. Instr. and Meth. B7/8 (1985) 657.

[7] B.M. Paine and B.X. Liu, in Ion Beam Assisted Film Growth, ed. T. Itoh (Elsevier, Amsterdam, 1989) p. 153.

[8] F.R. de Boer, R. Boom, W.C.M. Mattens, A.R. Miedema, and A.K. Niessen, Cohesion in Metals, eds. F.R. de Boer and D. Pettifor (North-Holland, Amsterdam, 1988).

[9] P.I. Loeff, A.W. Weeber, and A.R. Miedema, J. LessCommon Met. 140 (1988) 299.

[10] Y.-T. Cheng, X.-A. Zhao, T. Banwell, T.W. Workman, M-A. Nicolet, and W.L. Johnson, J. Appl. Phys. 60 (1986) 2615.

[11] Y.-T. Cheng, Phys. Rev. B40 (1989) 7403.

[12] M. Doyama and J.S. Koehler, Acta Metall. 24 (1976) 871.

[13] R.S. Averback and H. Hahn, Phys. Rev. B37 (1988) 10383.

[14] F.-R. Ding, R.S. Averback, and H. Hahn, J. Appl. Phys. 64 (1988) 1785.

[15] F.-R. Ding, P.R. Okamoto, and L.E. Rehn, Nucl. Instr. and Meth. B39 (1989) 122.
[16] F.-R. Ding, P.R. Okamoto, and L.E. Rehn, Mater. Res. Soc. Symp. Proc. 100 (1988) 69.

[17] R.B. Schwarz and W.L. Johnson, Phys. Rev. Lett. 51 (1983) 415;

J.C. Barbour, R. de Reus, A.W. Denier van der Gon, and F.W. Saris, J. Mater. Res. 2 (1987) 168;

O. Thomas, F.M. d'Heurle and A. Charai, Philos. Mag. B58 (1988) 529.

[18] J. Bøttiger, K. Dyrbye, K. Pampus, and R. Poulsen, Philos. Mag. A59 (1989) 569.

[19] K.H.J. Buschow, J. Phys. F. Met. Phys. 14 (1984) 593.

[20] Z. Altounian, Tu Guo-Hua, and J.O. Strom-Olsen, J. Appl. Phys. 54 (1983) 3111.

[21] K.H.J. Buschow, J. Less-Common Met. 79 (1981) 243.

[22] E. Hellstern and L. Schultz, Appl. Phys. Lett. 49 (1986) 1163.

[23] J.P.W.B. Duchateau, H.C. Tissink, G.J. van der Kolk, J. Verhoeven and F.W. Saris, Proc. 7th Int. Conf. on Ion and Plasma Assisted Techniques (CEP Consultants Ltd., Edinburgh, UK, 1989) p. 373.

[24] A. Polman, A.M. Vredenberg, W.H. Urbanus, P.J. van Deenen, S. Doorn, J. Derks, J. ter Beek, H. Alberda, H. Krop, I. Attema, E. de Haas, H. Kersten, S. Roorda, R. Schreutelkamp, J.G. Bannenberg, and F.W. Saris, Nucl. Instr. and Meth. B37/38 (1989) 935.

[25] J.F. Zicgler, J.P. Biersack, and U. Littmark, The Stopping and Range of Ions in Solids, vol. 1 (Pergamon Press, New York, 1985).

[26] L.R. Doolittle, Nucl. Instr. and Meth. B9 (1985) 344.

[27] Powder diffraction file 27-997, (International Centre for Diffraction Data, Swarthmore, USA).

[28] Diffraction patterns for $\mathrm{Ni}_{2} \mathrm{Zr}, \quad \mathrm{Ni}_{5} \mathrm{Zr}$, and $\mathrm{Ni}_{10} \mathrm{Zr}_{7}$ (spacegroup $\mathrm{Pbca}$ ) calculated after crystallographic data from Pearson's Handbook of Crystallographic Data for Intermetallic phases by P. Villars and L.D. Calvert (American Society for Metals, Metals Park, 1985).

[29] Z. Altounian, E. Batalla, J.O. Strom Olsen, and J.L. Walter, J. Appl. Phys. 61 (1987) 149.

[30] J. Bøttiger, N.J. Mikkelsen, S.K. Nielsen, G. Weyer, and K. Pampus, J. Non-Cryst. Solids 76 (1985) 303.

[31] B. Walz, P. Oelhafen, H.-J. Güntherodt, and A. Baiker, Appl. Surf. Sci. 37 (1989) 337.

[32] R. de Reus, H.C. Tissink, and F.W. Saris, J. Mater. Res. 5 (1990) 341.

[33] Powder diffraction file 26-809.

[34] Powder diffraction file 28-442.

[35] Powder diffraction file 5-681.

[36] Powder diffraction file 4-788.

[37] Powder diffraction file 16-868.

[38] Powder diffraction file 25-922.

[39] A.M. Brown and M.F. Ashby, Acta Metall. 28 (1980) 1085 .

[40] C.P. Flynn, Point Defects and Diffusion (Clarendon Press, Oxford, 1972) p. 78.

[41] P.G. Shewmon, Diffusion in Solids (McGraw Hill, New York, 1963) p. 74.

[42] A.D. Franklin, in: Point Defects in Solids, Vol. 1. General and Ionic Crystals, eds. J.H. Crawford, Jr. and L.M. Slifkin (Plenum Press, New York-London, 1972), p. 27. 
[43] B. Rauschenbach, Phys. Status Solidi 102 (1987) 645.

[44] A. Müller, V. Naundorf, and M.-P. Macht, J. Appl. Phys. 64 (1988) 3445.

[45] F. Besenbacher, J. Bottiger, S.K. Nielsen, and H.J. Whitlow, Appl. Phys. A29 (1982) 141.

[46] K. Hohmuth, V. Heera, and B. Rauschenbach, Nucl. Instr. and Meth. B39 (1989) 136.

[47] D.A. Lilienfield, L.S. Hung, and J.W. Mayer, Nucl. Instr. and Meth. B19/20 (1987) 1.

[48] Y. Kido, Nucl. Instr, and Meth. B37/38 (1989) 696.

[49] D.M. Follstaedt and J.A. Knapp, J. Appl. Phys. 59 (1986) 1756.

[50] D.A. Lilienfield, M. Nastasi, H.H. Johnson, D.G. Ast, and J.W. Mayer, Phys. Rev. Lett. 55 (1985) 1587.

[51] J.D. Budai and M.D. Aziz, Phys. Rev. B33 (1986) 2877.

[52] E. Ma, A.J. Brunner, T.W. Workman, C.W. Nieh, X.-A. Zhao, and M-A. Nicolet, Mater. Res. Soc. Symp. Proc. 100 (1988) 75 .

[53] N. Karpe, L.U. Aaen Andersen, K. Dyrbye, J. Bøttiger, and K.V. Rao, Phys. Rev. B39 (1989) 9874.

[54] D.A. Lilienfield and J.W. Mayer, Mater. Res. Soc. Symp. Proc. 74 (1987) 339.

[55] J. Bøttiger, S.K. Nielsen, and P.T. Thorsen, in: Amorphous Materials and Non-Equilibrium Processing, edited by $M$. von Allmen, (Les Editions de Physique, Les Ulis Cedex, 1984) p. 111.

[56] F. Priolo, J.M. Poate, D.C. Jacobson, J. Linnros, J.L. Batstone, and U. Campisano, Mater. Res. Symp. Proc. $100(1988) 87$.

[57] A.J. Barcz, B.M. Paine, and M-A. Nicolet, Appl. Phys. Lett. 44 (1985) 45.

[58] A.H. Hamdi and M-A. Nicolet, Thin Solid Films 119 (1984) 357.

[59] J.W. Mayer, B.Y. Tsaur, S.S. Lau, and L-S. Hung, Nucl. Instr. and Meth. 182/183 (1981) 1.
[60] J. Koike, P.R. Okamoto, and M. Meshii, Mater. Res. Soc. Symp. Proc. 100 (1988) 57

[61] J. Koike, P.R. Okamoto, L.E. Rehn, and M. Meshii, Mater. Res. Suc. Symp. Proc. 128 (1989) 339.

[62] J. Koike, P.R. Okamoto, L.E. Rehn, and M. Meshii, J. Mater. Res. 4 (1989) 1143.

[63] A.M. Ibrahim, Nucl. Instr. and Meth. B34 (1988) 135.

[64] U. Scheuer, L.E. Rehn, and P. Baldo, Mater. Res. Soc. Symp. Proc. 128 (1989) 213.

[65] J.L. Brimhall, Nucl. Instr. and Meth. B7/8 (1985) 26.

[66] G. Vályi, H. Ryssel, and W. Möller, Nucl. Instr. and Meth. B39 (1989) 268.

[67] B.V. King, D.G. Tonn, and I.S.T. Tsong, Nucl. Instr. and Meth. B7/8 (1985) 607.

[68] U.G. Akano, D.A. Thompson, W.W. Schmeltzer, and J.A. Davies, J. Mater. Res. 3 (1988) 1063.

[69] R.S. Averback, L.J. Thompson, Jr, J. Moyle, and M. Schalit, J. Appl. Phys. 53 (1982) 1342.

[70] L.S. Hung, J.W. Mayer, C.S. Pai, and S.S. Lau, J. Appl. Phys. 58 (1985) 1527.

[71] K. Affolter, X-A. Zhao, and M-A. Nicolet, J. Appl. Phys. 58 (1985) 3087.

[72] M. Nastasi, D.A. Lilienfield, H.H. Johnson, and J.W. Mayer, J. Appl. Phys. 59 (1986) 4011.

[73] K. Maex, R.F. de Keersmaeker, M. van Rossum, and W.F. van der Weg, Mater. Res. Soc. Symp. Proc. 100 (1988) 63.

[74] K. Kohlhof, S. Mantl, and B. Stritzker, Mater. Res. Soc. Symp. Proc. 74 (1987) 443.

[75] K. Maex, R.F. de Keersmaeker, M. van Rossum, W.F. van der Weg, and G. Krooshof, Nucl. Instr. and Meth. B19/20 (1987) 731 .

[76] B.M. Paine, M-A. Nicolet, and T.C. Banwell, Mater. Res. Soc. Symp. Proc. 7 (1982) 79.

[77] R. de Reus and F.W. Saris, Mater. Lett. 9 (1990) 487. 